\title{
Associations between dietary-choline intake, B-vitamins and anxiety levels
}

\author{
C. Foster-Brown ${ }^{1}$, K. Harrison ${ }^{1}$, Dr. C. Kelaiditis ${ }^{2}$, L. Pilic ${ }^{1}$ and Dr. Y. Mavrommatis ${ }^{1}$ \\ ${ }^{1}$ School of Health and Social Sciences, St. Mary's University, Twickenham, TW1 4SX and \\ ${ }^{2}$ Roehampton University, Grove House, Roehampton Lane, London, SW15 5PJ, UK
}

In the UK, an estimated 1 in 6 people over 16 years are symptomatic of common mental disorders (CMD). In 2014, generalised anxiety-disorder was the largest contributor to CMD. Anxiety related disorders cost the UK economy approximately £8.9 billion/ year resulting from factors including NHS costs, reduced employment and productivity. Deficiencies in specific nutrients can contribute to increased anxiety levels. Such nutrients include choline and B-vitamins which are essential nutrients that act as co-enzymes in numerous enzymatic biological pathways and contribute to one carbon-metabolism ${ }^{(1)}$. Research suggests associations between deficiencies in nutrients required for one carbon- metabolism and anxiety/depression ${ }^{(2,3)}$. However, research is limited concerning anxiety, prompting a requirement for further studies. Evidence proposes that increased anxiety levels may result from reduced acetylcholine synthesis, and/or increased homocysteine levels. Research suggests that low-intakes of B-vitamins/choline/betaine may result in reduced synthesis of S-adenosylmethionine (SAM) for deoxyribonucleic acid methylation and acetylcholine synthesis. The aim of this study was to explore the associations between reported dietary choline-intakes (RDCI), reported dietary B-vitamin (B6, B9, B12) intakes (RDBI) and anxiety levels.

This was an observational, cross-sectional study. Thirty-six participants were recruited $(18-50$ years $)($ males $=10$ and females $=26)$. Anxiety data was collated via the Hospital Anxiety and Depression Score questionnaires. RDCI and RDBI were estimated via 3-day food diaries.

Mann Whitney U-tests revealed that anxiety levels were greater for females (median $(\mathrm{IQR})=10(5), \mathrm{n}=26)$ than for males $($ median $(\mathrm{IQR})=5(2.5), \mathrm{n}=10), \mathrm{U}=64.0, \mathrm{p}=0.019$, that vitamin $\mathrm{B}_{12}$-intakes were significantly lower for females $($ median $(\mathrm{IQR})=3.4 \mu \mathrm{g} / \mathrm{day}$ $(1.8 \mu \mathrm{g} / \mathrm{day}), \mathrm{n}=26)$ than for males (median $(\mathrm{IQR})=6.3 \mu \mathrm{g} / \mathrm{day}(2.9 \mu \mathrm{g} / \mathrm{day}), \mathrm{n}=10), \mathrm{U}=48.5, \mathrm{p}=0.004$, and methionine-intakes were significantly less for females (median $(\mathrm{IQR})=1.8 \mathrm{~g} / \mathrm{day}(1.3 \mathrm{~g} / \mathrm{day}), \mathrm{n}=26)$ than for males $(\operatorname{median}(\mathrm{IQR})=2.9 \mathrm{~g} / \mathrm{day}(1.1 \mathrm{~g} / \mathrm{day}), \mathrm{n}=10)$, $\mathrm{U}=65.5, \mathrm{p}=0.023$. Spearman's correlation tests established moderate negative correlations between methionine-intakes and anxiety levels $\left(r_{s}=-0.379, \mathrm{p}=0.023\right)$, and vitamin $\mathrm{B}_{12}$-intakes and anxiety levels $\left(r_{s}=-0.372, \mathrm{p}=0.025\right)$. Considering potential confounding of sex, sex-stratified correlation analysis between methionine/vitamin $\mathrm{B}_{12}$ and anxiety levels was conducted. A strong, negative correlation was observed between methionine-intakes and anxiety levels only in males $\left(r_{s}=-0.711, \mathrm{p}=0.021\right)$. No significant correlations were established between RDCI and anxiety, $p>0.05$.

These results highlight the need to take into account potential confounding of sex when exploring associations between dietary intake and anxiety levels. Negative association between methionine and anxiety levels in males may be explained by the role of methionine in synthesis of SAM, that has been associated with anxiety/depression ${ }^{(3)}$. The fact similar was not observed in females, may be due to protective effects of oestrogen on inducing endogenous synthesis of SAM. Considering a small sample size, these results and hypotheses should be confirmed in a larger sample size study.

Nevertheless, choline and B-vitamins are essential nutrients and their biological interactions need consideration in the UK. Large randomised controlled trials and association studies will increase statistical/study power, facilitating data essential for dietary-intake recommendations for choline and B-vitamins.

\section{References}

1. O. Kennedy D (2016) Nutrients 8, 68

2. Bjelland I, Tell GS, Vollset SE et al. (2009) Am J Clin Nutr 90, 1056-60.

3. Mischoulon D \& Fava M (2002) J Clin Psychiatry 76, 1158S-1161S. 